Article

\title{
Application of Computational Fluid Dynamics in Chlorine-Dynamics Modeling of In-Situ Chlorination Systems for Cooling Systems
}

\author{
Jongchan Yi ${ }^{1}{ }^{\oplus}$, Jonghun Lee ${ }^{1}$, Mohd Amiruddin Fikri ${ }^{2,3}$, Byoung-In Sang ${ }^{4}(\mathbb{D}$ and \\ Hyunook Kim ${ }^{1, *(D)}$ \\ 1 Department of Environmental Engineering, University of Seoul, Seoul 02504, Korea; harooi7@uos.ac.kr (J.Y.); \\ jonghunlee@uos.ac.kr (J.L.) \\ 2 Faculty of Bioengineering and Technology, Universiti Malaysia Kelantan (Jeli Campus), Jeli 17600, Kelantan, \\ Malaysia; amirfikri@moh.gov.my \\ 3 Engineering Division, Jabatan Kesihatan Negeri Kelantan, Kota Bharu 15590, Kelantan, Malaysia \\ 4 Department of Chemical Engineering, Hanyang University, 222 Wangsimniro, Seongdong-gu, \\ Seoul 04763, Korea; biosang@hanyang.ac.kr \\ * Correspondence: h_kim@uos.ac.kr; Tel.: +82-2-6490-2871; Fax: +82-2-6490-2859
}

Received: 4 May 2020; Accepted: 24 June 2020; Published: 28 June 2020

\begin{abstract}
Chlorination is the preferred method to control biofouling in a power plant cooling system due to its comparative effectiveness and low cost. If a power plant is located in a coastal area, chlorine can be electrochemically generated in-situ using seawater, which is called in-situ electro-chlorination; this approach has several advantages including fewer harmful chlorination byproducts and no need for chlorine storage. Nonetheless, this electrochemical process is still in its infancy in practice. In this study, a parallel first-order kinetics was applied to simulate chlorine decay in a pilot-scale cooling system. Since the decay occurs along the water-intake pipe, the kinetics was incorporated into computational fluid dynamics (CFD) codes, which were subsequently applied to simulate chlorine behavior in the pipe. The experiment and the simulation data indicated that chlorine concentrations along the pipe wall were incremental, even under the condition where a strong turbulent flow was formed. The fact that chlorine remained much more concentrated along the pipe surface than in the middle allowed for the reduction of the overall chlorine demand of the system based on the electro-chlorination. The cooling system, with an in-situ electro-chlorination, consumed only $1 / 3$ of the chlorine dose demanded by the direct injection method. Therefore, it was concluded that in-situ electro-chlorination could serve as a cost-effective and environmentally friendly approach for biofouling control at power plants on coastal areas.
\end{abstract}

Keywords: computational fluid dynamics; power plant; cooling system; electro-chlorination; in-situ chlorination

\section{Introduction}

Power plants intake massive amounts of water for their cooling systems. Typically, nuclear and coal-combustion power plants use cooling water at rates of $100-220 \mathrm{~m}^{3} \mathrm{hr}^{-1}$ to generate $1 \mathrm{MW}$ of electricity [1-3]. Since nuclear power plants typically produce $1000 \mathrm{MW}$ of electricity [4], such plants are frequently built on coasts, where $28-60 \mathrm{~m}^{3} \mathrm{sec}^{-1}$ of water can be easily supplied for their cooling systems. The raw seawater drawn into the cooling systems also contains a variety of organisms. These sea organisms often grow within the inner surface of cooling pipe, potentially leading to issues such as increased pumping-load, corrosion, and reduced heat-exchange efficiency $[5,6]$. For example, more than $5 \%$ of condenser efficiency could be lost owing to bio-growth (or biofouling) within a cooling 
pipe [7]. The economic impact of biofouling on a $550 \mathrm{MW}$ power plant is estimated to be $\$ 0.93$ million annually [8].

Over other biocidal options, the effectiveness and low cost of chlorination make it the preferred method to prevent sea-organism growth and biofouling. Chlorination is generally conducted by directly injecting chlorine into pipes or by electrochemically producing chlorine using seawater in water-intake pipes. The latter is called in-situ electro-chlorination, and a few of its advantages include the reduced production of harmful byproducts and the elimination of chlorine storage needs [9]. Furthermore, if electrodes are prepared with an optimized shape and installed at appropriate intervals near the inner surface of water-intake pipes, in-situ electro-chlorination can be controlled to maintain a relatively high concentration of chlorine specifically near the pipe wall, where biofouling occurs. However, due to the difficulty in optimizing its operational conditions, few attempts have been made to apply in-situ electro-chlorination in practice [10].

The chlorine concentration is a main factor to be controlled in chlorination systems. Chlorine levels should be controlled considering the following: First, a minimum residual chlorine concentration should be determined and maintained to ensure effective anti-biofouling. It is known that chlorine concentration should be maintained above $0.05 \mathrm{mg} \mathrm{L}^{-1}$ in cooling water before it is drawn into the system; otherwise, biofouling can occur [11]. This in turn increases the minimum effective chlorine dosage [12]. However, the residual chlorine concentrations of used cooling water discharged to the sea should remain under a certain level to protect the costal environment. According to the European Integrated Pollution Prevention and Control [13], European countries require the total residual oxidants in used cooling water not to exceed $0.2 \mathrm{mg} \mathrm{L}^{-1}$ (daily average). Typically, the chlorine concentrations of cooling water employed by a power plant and the residual chlorine concentration of used water are maintained at $0.5-1.5 \mathrm{mg} \mathrm{L}^{-1}$ and $0.05-0.2 \mathrm{mg} \mathrm{L}^{-1}$, respectively $[6,11,12,14]$. However, it can be challenging to maintain chlorine concentration at these levels due to variations in water quality and flow rate of cooling water [11,12]. Therefore, models have been applied for predicting chlorine concentrations and determining the levels needed to prevent biofouling in pipes.

Several models to predict chlorine decay in bulk water have been suggested and evaluated. First-order kinetics is often applied for modeling chlorine decay in water. Since actual chlorine decay in real water is impacted by many reactants, first-order equations have been accurate enough to properly describe this process [15-18]. Some researchers deal with chlorine decay in two phases: a rapid-decaying phase and a slow-decaying phase. This approach has been successfully applied to predict decay in real water with acceptable levels of error and complexity [17,19-22].

Computational fluid dynamics (CFD) has developed remarkably over the past five decades. A great deal of progress has also been made in numerical techniques to get reliable results with low computational cost [23]. Therefore, the CFD is now widely applied by choosing proper numerical methods in the environmental field to deal with such complex systems. Incorporating fluid dynamics in modeling of chlorine fate in cooling systems could help to configure in-situ electro-chlorination systems. Several recent studies have focused on CFD simulation coupled with disinfection models. Such works aim to increase disinfection efficiency and reduce disinfectant dosing and byproduct formation [24-27] and are mostly focused on the impact of flow patterns on disinfectant behavior. Computational fluid dynamics considering chemical reactions in water supply systems has remained in its early stage due to challenges associated with validating and accurately defining unsteady flow rates and multi-phase flow conditions [24]. Nevertheless, CFD is considered an effective tool for modeling chlorine distribution through a system and its use is of interest [28].

In this study, we evaluate in-situ electro-chlorination in a pilot-scale cooling system using a CFD code including the chlorine decay kinetics in predicting the behavior of generated chlorine. Specifically, a cylindrical electrode was installed inside the water pipe to generate chlorine. The flow pattern of the cooling water through the pipe was modeled using the CFD code as well as the chlorine concentration of the cooling water flowing along the pipe. The chlorine concentration measured experimentally from the pilot-scale cooling system was then compared with simulation results. We believe that our study is 
the first attempt to accurately simulate chlorine behavior in a cooling system using a model integrating chlorine decay kinetics and CFD.

\section{Materials and Methods}

\subsection{Chlorine Kinetic Model}

Chlorine decay in seawater is often modeled using the first-order decay kinetics [20,29]. However, as this model only contains one parameter and does not consider other reactions potentially occurring in real water, it often fails to make an accurate prediction [20,30,31]. In this study, we evaluated in-situ electro-chlorination in a pilot-scale cooling system using a CFD code including the chlorine decay kinetics to predict the behavior of generated chlorine. This model consists of two parts: the first one represents the slow reaction (typically related to the presence of organic matters) while the other concerns the fast reaction (typically related to easily oxidizable matters, such as metals or simple organic chemicals in the water) [20]. The differential form of the model can be expressed as:

$$
\frac{d C}{d t}=-k_{f} C_{f}-k_{s} C_{s}
$$

The integrated form of the model is:

$$
C(t)=C_{0} z e^{-k_{s} t}+C_{0}(1-z) e^{-k_{f} t}
$$

where $C(t)$ is the chlorine concentration ( $\mathrm{mg} \mathrm{L}^{-1}$ ) at a given time; $C_{0}$ is the initial chlorine concentration $\left(\mathrm{mg} \mathrm{L}^{-1}\right) ; z$ is the fraction factor accounting for slow reaction; and $k_{s}$ and $k_{\mathrm{f}}$ are the first-order rate constants $\left(\mathrm{h}^{-1}\right)$ for the slow and fast reactions, respectively [32]. There have been various attempts to estimate these rate constants using water quality parameters such as chemical oxygen demand (COD), total organic carbon (TOC), dissolved organic carbon (DOC), salinity, $\mathrm{NH}_{4}{ }^{+}$, temperature, and $\mathrm{pH}[22,33-35]$. Moreover, the initial chlorine concentration is included, since a strong correlation is common between the chlorine decay rate and initial concentration [22,33]. We use the following equations to estimate the aforementioned model parameters as suggested by Al Heboos et al. [33]:

$$
\begin{aligned}
& k_{s}=p_{s} C_{0}^{-m_{s}} e^{n_{s} \text { TOC }} \\
& k_{f}=p_{f} C_{0}^{-m_{f}} e^{n_{f}} \text { TOC } \\
& z=d_{1} C_{0}^{d_{2}} \mathrm{TOC}^{-d_{3}}
\end{aligned}
$$

The coefficients, $p_{s}, p_{f}, m_{s}, m_{f}, n_{s}, n_{f}, d_{1}, d_{2}$, and $d_{3}$ must be estimated. In Equations (3)-(5), TOC is used as an indicator of the amount of organic matter in the water.

\subsection{Experimental Set-Up}

\subsubsection{Batch Kinetic Tests}

Batch kinetic tests were conducted to calibrate the model parameters. Artificial seawater (a $3 \%$ sea salt solution; this is the same salinity as the West Sea) with different TOC values (TOC 1, 2, and $3 \mathrm{mg} \mathrm{L}^{-1}$ ) was prepared by adding $15 \mathrm{~g}$ of sea salt (Sigma-Aldrich, St. Louis, MO, USA) to $500 \mathrm{~mL}$ of distilled water. The TOC of the synthesized seawater was adjusted by adding humic acids solution. The solution was prepared by dissolving $116.5 \mathrm{mg}$ of humic acid powder (Sigma-Aldrich, St. Louis, MO, USA) into $1 \mathrm{~L}$ of distilled water. To force the humic acids to dissolve in water, the water $\mathrm{pH}$ was adjusted to 10 by adding $0.1 \mathrm{M} \mathrm{NaOH}$. Then, the $\mathrm{pH}$ was readjusted to 7 using $0.1 \mathrm{M} \mathrm{HCl}$. Then, the solution was sonicated for $30 \mathrm{~min}$ and filtered through a $0.2 \mu \mathrm{m}$ polytetrafluoroethylene-membrane filter. The synthesized seawater was stored for $12 \mathrm{~h}$ at room temperature $\left(18-20^{\circ} \mathrm{C}\right)$ before use in experiments. 
A real seawater sample was taken from an area on the coast of the West Sea (Incheon, Korea). The collected seawater was filtered through a slow sand filter and subjected to UV irradiation for disinfection. The seawater characteristics were as follows: salinity: $2.83 \%, \mathrm{pH}: 7.89$, specific gravity: 1.023, TOC: $1.3 \mathrm{mg} \mathrm{L}^{-1}$.

To generate electrochemically-produced chlorine, two cylindrical electrodes were used in this study (Figure 1). A $\mathrm{RuO}_{2}$ electrode was used as an outer cathode and a Ti electrode was used as an inner anode. The $\mathrm{RuO}_{2}$ and Ti electrodes had diameters of 100 and $70 \mathrm{~mm}$, respectively. Both electrodes were $5 \mathrm{~mm}$ thick and $50 \mathrm{~mm}$ long as shown in Figure 1a. To quantify the amount of free chlorine produced by the $\mathrm{RuO}_{2} / \mathrm{Ti}$ electrodes, an experiment was performed using the West Sea water. First, $20 \mathrm{~L}$ seawater were placed in a $40 \mathrm{~L}$ bucket as shown in Figure $1 \mathrm{~b}$. The $\mathrm{RuO}_{2} / \mathrm{Ti}$ electrodes were then installed in the middle of the bucket. Four different electric currents (i.e., 10, 15, 20, and 25 A) supplied by a direct current (DC) power supply (TDP-3030B, Toyotech Co., Incheon, Korea) were tested. While the current was supplied to the electrodes, the seawater was completely mixed using an agitator. Water samples were collected from the bucket at a given time interval.

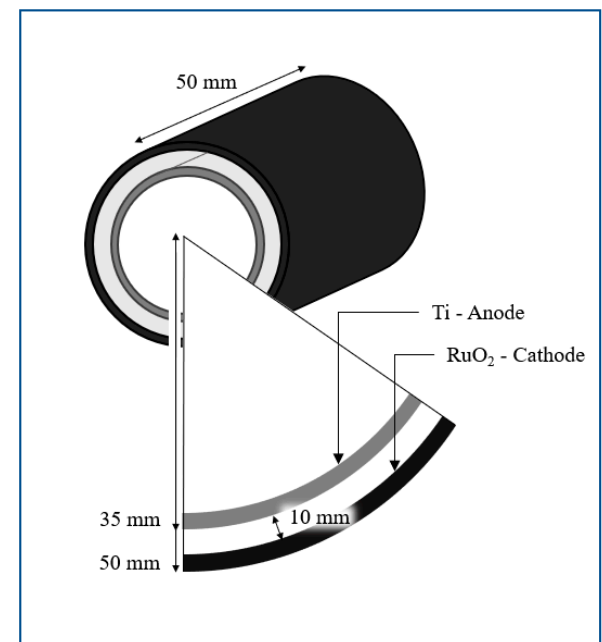

(a)

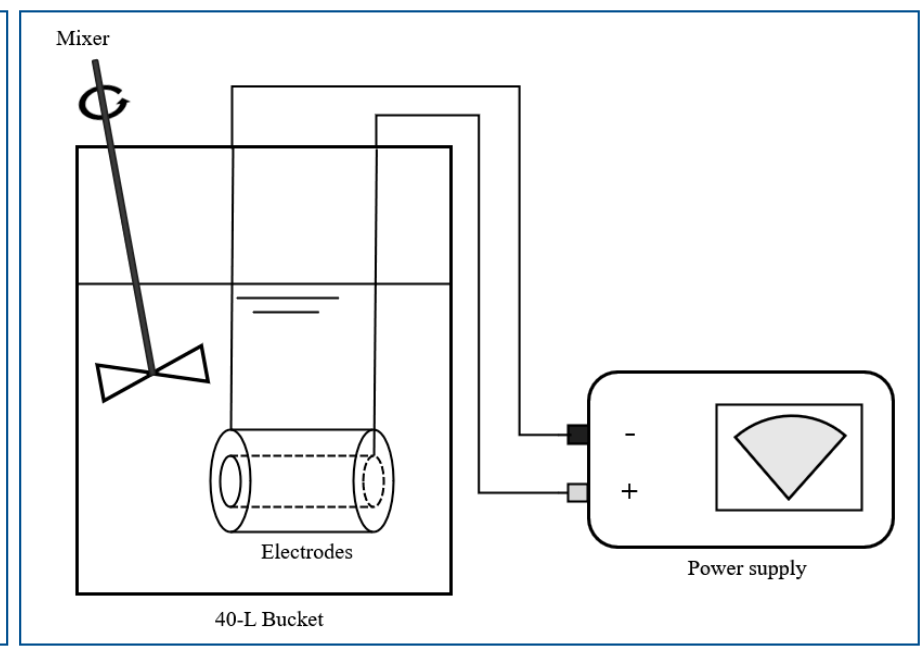

(b)

Figure 1. Electrodes and batch experiment set-up. (a) Two cylindrical electrodes used in this study. (b) Batch experiment set-up for kinetic tests.

\subsubsection{Pilot-Scale In-Situ Electro-Chlorination}

A pilot-scale cooling-water circulation system was prepared as shown in Figure 2. A water box (volume $=60 \mathrm{~L}$ ) was positioned in front of the water pipeline; it contained interior baffles to prevent the occurrence of a flow vortex before the water entered the pipeline. The system had a total of seven sampling ports: the first path of the pipeline had five ports (Nos. 1-5), and there was one port on the second and third paths each (Nos. 6 and 7). The sampling ports along the first path were installed at $30 \mathrm{~cm}$ apart. The pipeline pathways were spaced at $35 \mathrm{~cm}$ intervals. The water tank was prepared to supply seawater and the pump was operated at a flow rate of 600-900 $\mathrm{L} \mathrm{min}^{-1}$.

The pilot-scale cooling system with an in-situ electro-chlorination system was operated to confirm the chorine dynamics within the cooling system. The system was operated under different flow rates $\left(600,700,800\right.$, and $\left.900 \mathrm{~L} \mathrm{~min}^{-1}\right)$ under the same current (i.e., $\left.25 \mathrm{~A}\right)$. An aliquot of water sample $(10 \mathrm{~mL})$ was taken from each port at a given interval to measure free chlorine concentrations. 


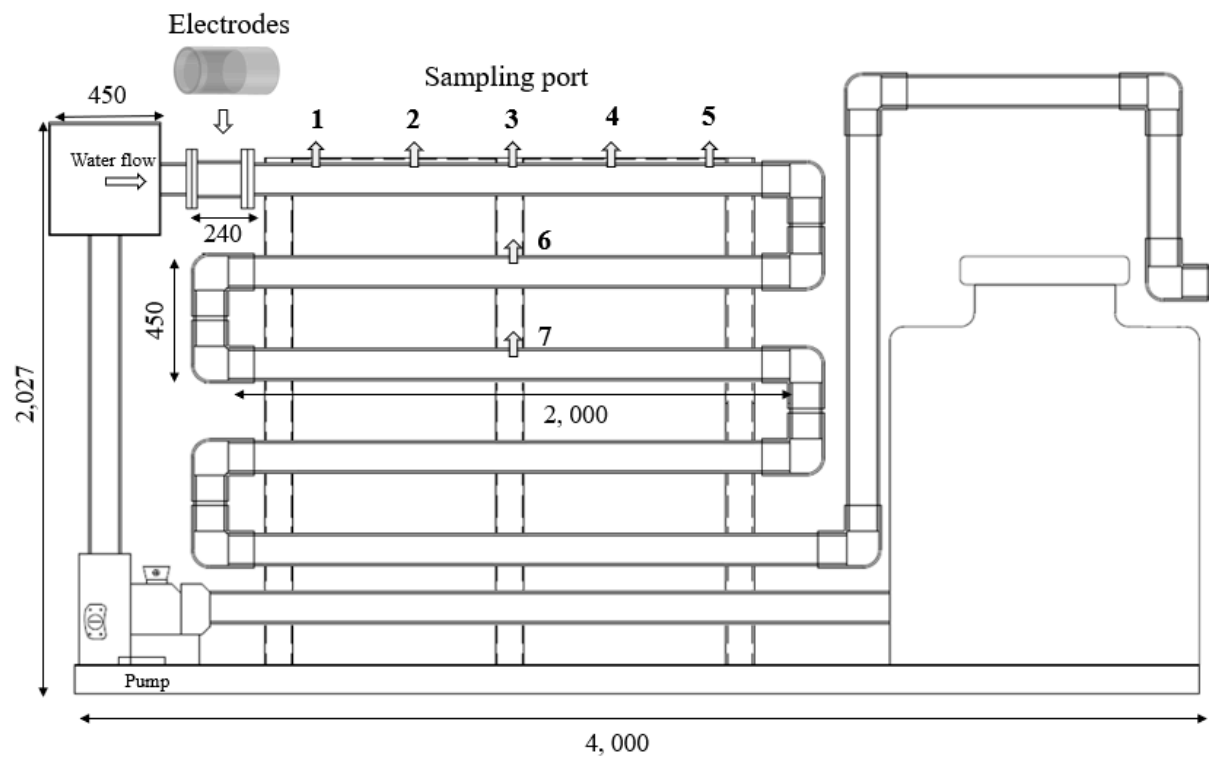

(a)

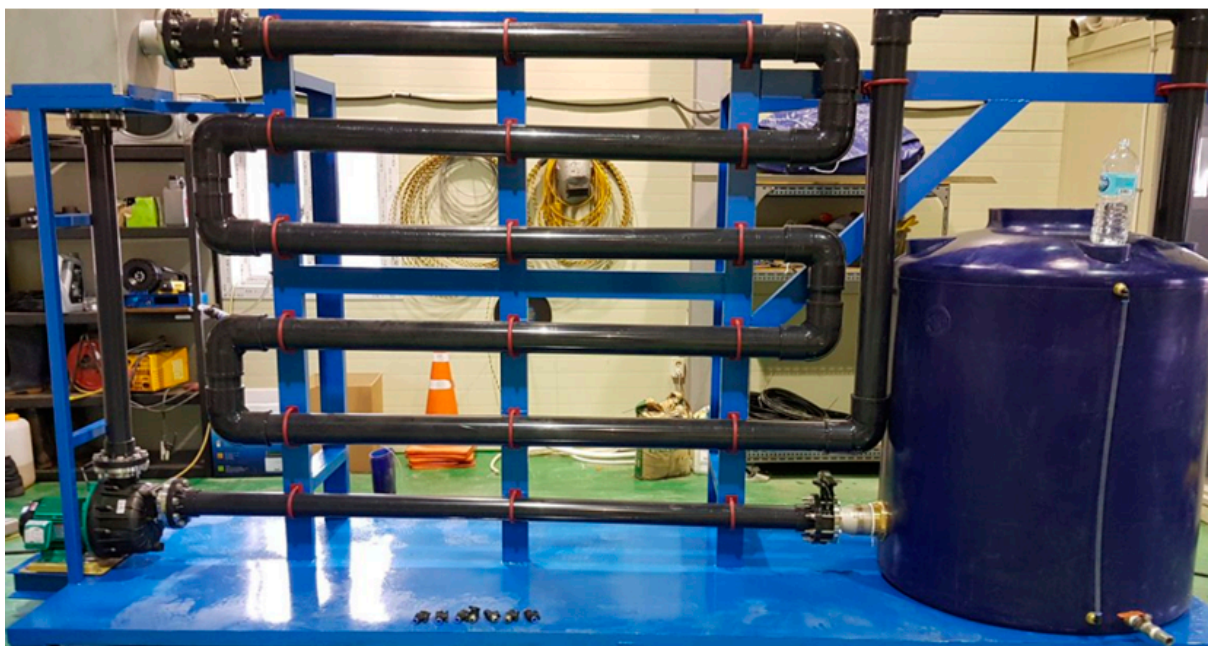

(b)

Figure 2. Schematic diagram for pilot-scale cooling-water circulation system (a) along with a real picture of the system (b).

\subsection{Analytical Methods}

All water samples were collected in triplicate and kept at $4{ }^{\circ} \mathrm{C}$ before measurement. Free chlorine measurement was carried out based on the United States Environmental Protection Agency Method 330.5 (measuring range: $0.02-2.00 \mathrm{mg} \mathrm{L}^{-1}$ ) [36]. The measurement was done within 3 min after injecting $\mathrm{N}, \mathrm{N}$-diethyl-1.4-phenylenediamine (DPD; Hach, Loveland, CO, USA) reagent into the sample. UV-Vis spectrophotometer (UV-2600 Spectrophotometers, Shimadzu, Kyoto, Japan) (measuring range: -5 to 5 Abs.) was used for the chlorine analysis. Total organic carbon (TOC) was determined using a TOC analyzer (ASI-L, Shimadzu, Kyoto, Japan) (measuring range: $4 \mu \mathrm{g} \mathrm{L}^{-1}$ to $30,000 \mathrm{mg} \mathrm{L}^{-1}$ ).

\subsection{Simulation Set-Up}

In this study, water flow through the pipeline was simulated using a commercial CFD package (Flow-3D v11.2.1.06, Flow Science Inc., Santa Fe, NM, USA). The simulation was conducted to investigate chlorine dynamics in the pilot-scale cooling system. The simulation domain was restricted to the first three pipeline paths covering seven sampling ports (Figure 2a). The boundary conditions 
of the simulation were set to reflect the dimensions of the pilot-scale in-situ electro-chlorination experiment. The flow rate was given at the inlet $\left(600,700,800\right.$, and $\left.900 \mathrm{~L} \mathrm{~min}^{-1}\right)$, while the pressure was specified at the outlet. The given pressure was obtained experimentally (see Table S1 for details). The other boundary conditions included the wall and symmetric conditions (mirrored along the symmetric surface). It was set that chlorine would be generated from the surface of the electrodes $\left(\right.$ mass time $^{-1}$ ). Since electrochemically generated chlorine would have higher density than water $\left(>1.2 \mathrm{~kg} \mathrm{~L}^{-1}\right)$, two different density flows were applied to simulate flows of seawater with and without chlorine; the water containing chlorine flows on the surface of electrodes. The chemical reactions between chlorine and oxidant-demanding matters in seawater were modeled using Equations (1)-(5) and (9). The other simulation parameters and physical model structures are described in detail in Section S2 of the Supplementary Materials. In addition, the mesh-independent test can be found in Section S3.

\section{Results and Discussion}

\subsection{Model Application}

Nine sets of kinetics studies were conducted using artificial seawater to calibrate each coefficient. The coefficients, $d_{1}, p_{s}$, and $\mathrm{mf}$ were chosen as important coefficients via sensitivity tests (see Section $\mathrm{S} 1$ and Figure S1). The estimation of each coefficient was performed in the order of the sensitivity-test results as shown in Table 1 and Figure 3. The coefficients were carefully estimated to minimize the total root mean square error (RMSE); the condition for model calibration is presented in Section S1. Then, kinetics constants for the parallel first-order decay model are estimated as follows:

$$
\begin{aligned}
& k_{s}=1.01 C_{0}^{-0.005} e^{0.02 ~ T O C} \\
& k_{f}=33.7 C_{0}^{-0.002} e^{0.67 \text { TOC }} \\
& z=0.355 C_{0}^{0.11} \mathrm{TOC}^{-0.10}
\end{aligned}
$$

Based on Equations (6)-(8), it can be assumed that more chlorine would be consumed by the fast reaction than the slower one, since the fraction of the slow reaction $(z)$ changes little or remains stable within the range of $0.2-0.5$ under typical seawater conditions.

The estimated constants and correlation factors for each case are summarized in Table 1, and the fittings are also presented in Figure 3. As shown in Table 1, the slow reaction rate constant varied little compared to that of the fast reaction under the given conditions.

\begin{tabular}{|c|c|c|c|c|c|c|c|}
\hline \multirow{2}{*}{ Sample } & \multirow{2}{*}{$\begin{array}{l}\text { TOC Concentration } \\
(\mathrm{mg} \mathrm{L}-1)\end{array}$} & \multirow{2}{*}{$\begin{array}{c}\text { Initial Chlorine } \\
\text { Dose (mg L-1) }\end{array}$} & \multicolumn{3}{|c|}{ Estimated Constants } & \multirow{2}{*}{$\mathbf{R 2}$} & \multirow{2}{*}{ RMSE } \\
\hline & & & $k_{s}\left(\mathrm{~h}^{-1}\right)$ & $k_{f}\left(\mathrm{~h}^{-1}\right)$ & $\mathbf{z}$ & & \\
\hline \multirow{9}{*}{$\begin{array}{l}\text { Artificial } \\
\text { seawater }\end{array}$} & \multirow{3}{*}{1.0} & 1.2 & 1.029 & 65.83 & 0.362 & 0.776 & 0.190 \\
\hline & & 1.8 & 1.027 & 65.78 & 0.379 & 0.880 & 0.134 \\
\hline & & 2.4 & 1.026 & 65.74 & 0.391 & 0.924 & 0.138 \\
\hline & \multirow{3}{*}{2.0} & 1.2 & 1.050 & 128.7 & 0.338 & 0.910 & 0.057 \\
\hline & & 1.8 & 1.048 & 128.6 & 0.353 & 0.944 & 0.120 \\
\hline & & 2.4 & 1.047 & 128.5 & 0.365 & 0.943 & 0.090 \\
\hline & \multirow{3}{*}{3.0} & 1.2 & 1.071 & 251.4 & 0.325 & 0.603 & 0.064 \\
\hline & & 1.8 & 1.069 & 251.2 & 0.339 & 0.853 & 0.110 \\
\hline & & 2.4 & 1.068 & 251.1 & 0.350 & 0.809 & 0.154 \\
\hline \multirow{3}{*}{$\begin{array}{l}\text { West Sea } \\
\text { seawater }\end{array}$} & \multirow{3}{*}{1.3} & 1.2 & 1.036 & 80.49 & 0.353 & 0.885 & 0.109 \\
\hline & & 1.8 & 1.034 & 80.43 & 0.369 & 0.941 & 0.194 \\
\hline & & 2.4 & 1.032 & 80.38 & 0.381 & 0.905 & 0.143 \\
\hline
\end{tabular}

Table 1. Estimated kinetics parameters depending on total organic carbon (TOC) and initial chlorine dose. RMSE = root mean squared error. 

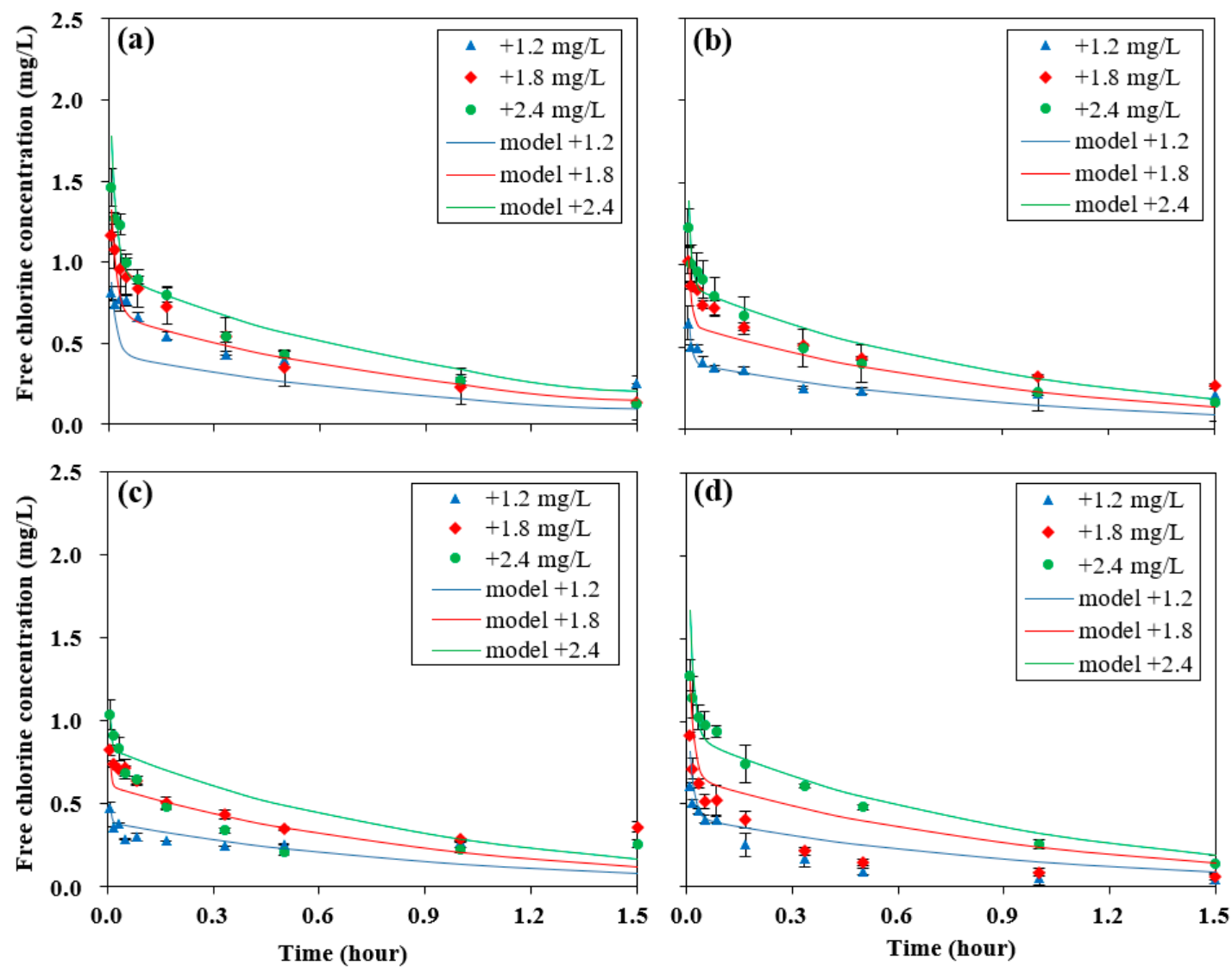

Figure 3. Free chlorine decay curves in seawater with different TOC and initial chlorine concentration. Each line represents the predicted concentration of chlorine under a given condition. (a) Artificial seawater solution with $1 \mathrm{mg} \mathrm{L} \mathrm{m}^{-1}$ of TOC; (b) artificial seawater solution with $2 \mathrm{mg} \mathrm{L}^{-1}$ of TOC; (c) artificial seawater solution with $3 \mathrm{mg} \mathrm{L}^{-1}$ of TOC; (d) West Sea water (1.3 $\mathrm{mg} \mathrm{L}^{-1}$ of TOC).

Notably, both reaction rate constants were more affected by TOC levels than by initial chlorine concentration. Moreover, the fast reaction rate constant varied considerably according to the TOC level of the seawater. We observed an inverse relationship between the initial chlorine concentration and first-order kinetics coefficient as reported by others [22,33]; however, the correlation was not strong compared to that between TOC and $k$. In other words, the rate constants did not change much depending on $C_{0}$, because the exponential part of $C_{0}$ in this study was very small. Fortunately, this can be an advantage in determining the rate constants for in-situ electro-chlorination, because there is no "initial concentration" in in-situ electro-chlorination. In the simulation, the electrode served as the mass source for chlorine generation, and the chlorine concentration in each cell (control volume) was calculated by the internal solver of Flow-3D in accordance with the surrounding flow.

The injected chlorine decayed rapidly within one minute and then decayed more gradually, as shown in Figure 3. Although there are some small variations between the predicted and measured data, the model describes the chlorine decay in seawater well. The correlation between the model and experimental data is depicted in Figure 4; the coefficient of determination $\left(R^{2}\right)$ was 0.919 .

For in-situ electro-chlorination, the initial chlorine concentration in the control volume facing the electrode $\left(C_{s}\right)$ was defined in this study and determined as follows:

$$
C_{s}=r_{e} / Q
$$

where $r_{e}$ is the chlorine-forming rate of an electrode under a given condition $\left(\mathrm{mg} \mathrm{min}{ }^{-1}\right)$ and $Q$ is the flow rate $\left(\mathrm{L} \mathrm{min}^{-1}\right)$. The chlorine-forming rate must be obtained experimentally because it changes according to the material of the electrode, current density, electrode gap, and the presence of electrolytes. 


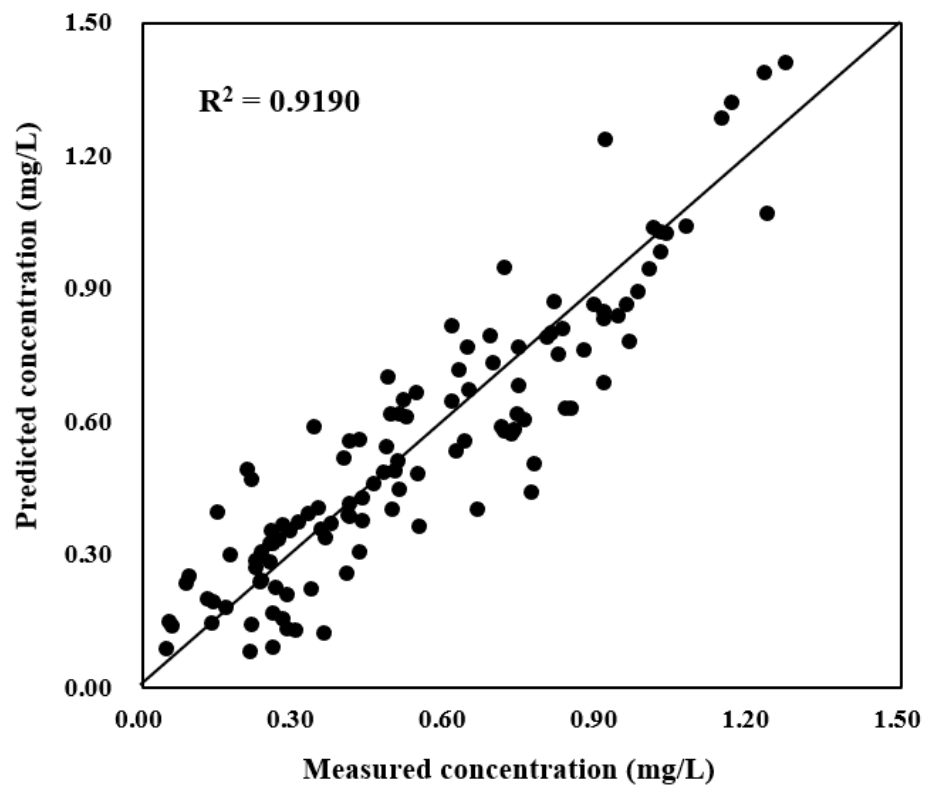

Figure 4. Correlation between model and experimental data in the chlorine kinetics using seawater.

Many studies determined the rate constants using kinetic data from experiments conducted over the course of several hours, sometimes over $100 \mathrm{~h}[17,18,30]$. It is possible to obtain a well-fitted curve by reducing the number of samples taken during the first few minutes before the chlorine concentration stabilizes and focusing on samples drawn after the initial oxidant demand period. However, the retention time of seawater in a cooling system is generally less than $30 \mathrm{~min}$ [12]. Thus, the model should be fitted to data collected within an hour to better predict the performance of the cooling system.

\subsection{In-Situ Electro-Chlorination Experiment with CFD Simulation}

In-situ electro-chlorination tests were conducted to obtain the chlorine-forming rate of $\mathrm{RuO}_{2} / \mathrm{Ti}$ electrodes under different current conditions. Figure 5 shows free chlorine concentrations under different current conditions. The concentration of free chlorine linearly increased with chlorination time. The expected chlorine-forming rates under 10, 15, 20, and 25 A were 101, 164, 278, and $381 \mathrm{mg} \mathrm{min}^{-1}$, respectively. The effective chlorine concentration for biofouling control in power plants is reported to be $0.5-1.5 \mathrm{mg} \mathrm{L}^{-1}[6,11,12,14]$. To meet this minimum chlorine concentration, $25 \mathrm{~A}$ was chosen for the electro-chlorination experiment and was expected to result in a chlorine concentration of $0.4-0.6 \mathrm{mg} \mathrm{L}^{-1}$ in the end of the pipe after mixing (point 7). Thus, the artificial concentration was $0.64,0.54,0.48$, and $0.42 \mathrm{mg} \mathrm{L}^{-1}$ for the flow rates of $600,700,800$, and $900 \mathrm{~L} \mathrm{~min}^{-1}$, respectively.

The in-situ electro-chlorination results are shown in Figure 6. The measured chlorine concentration at each sampling point and the calculated concentration obtained via the CFD simulation were compared under different flow rates. In both cases, model calculated values reasonably followed the measured ones. The chlorine concentrations gradually decreased due to the diffusion while the water passed through the first pipe containing sampling ports 1-5. After that, the concentrations remained relatively stable through the second and third pipes (which correspond to sampling ports 6 to 7 ) because the chlorine became fully mixed with the seawater when it passed through the pipes bent at $180^{\circ}$ (circled with a red-dotted line in Figure 7). This phenomenon is more marked in the simulated results due to experimental error. The red-dotted line in Figure 6 represents the desirable concentration. As expected, the chlorine concentrations near the wall remained higher than the artificial concentration prior to ports 6 and 7. This chlorine dispersion is clearly shown in the simulation. Figure 7 shows three types of fluid contours, chlorine concentration (Figure 7a,b), velocity magnitude (Figure 7c), and pressure (Figure $7 \mathrm{~d}$ ). As shown in Figure 7a,b, the generated chlorine flowed along the pipe and gradually 
diffused through seawater. Thus, chlorine concentrations can vary throughout the length of the pipe, as is further discussed in Section 3.3.

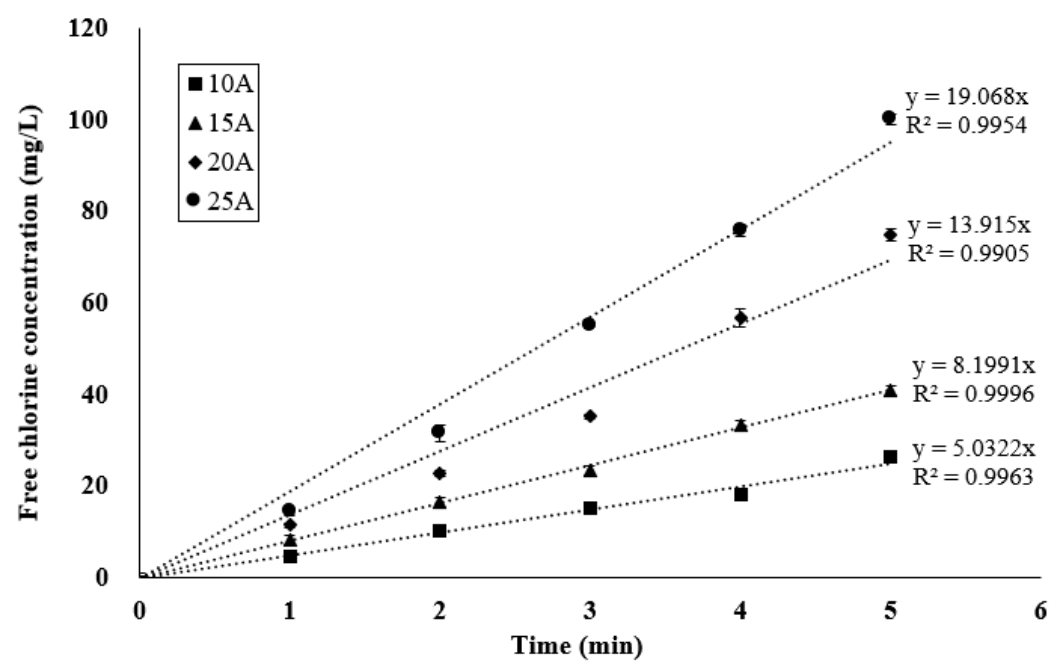

Figure 5. Free chlorine concentrations in West Sea water under different current conditions in an in-situ electro-chlorination system.
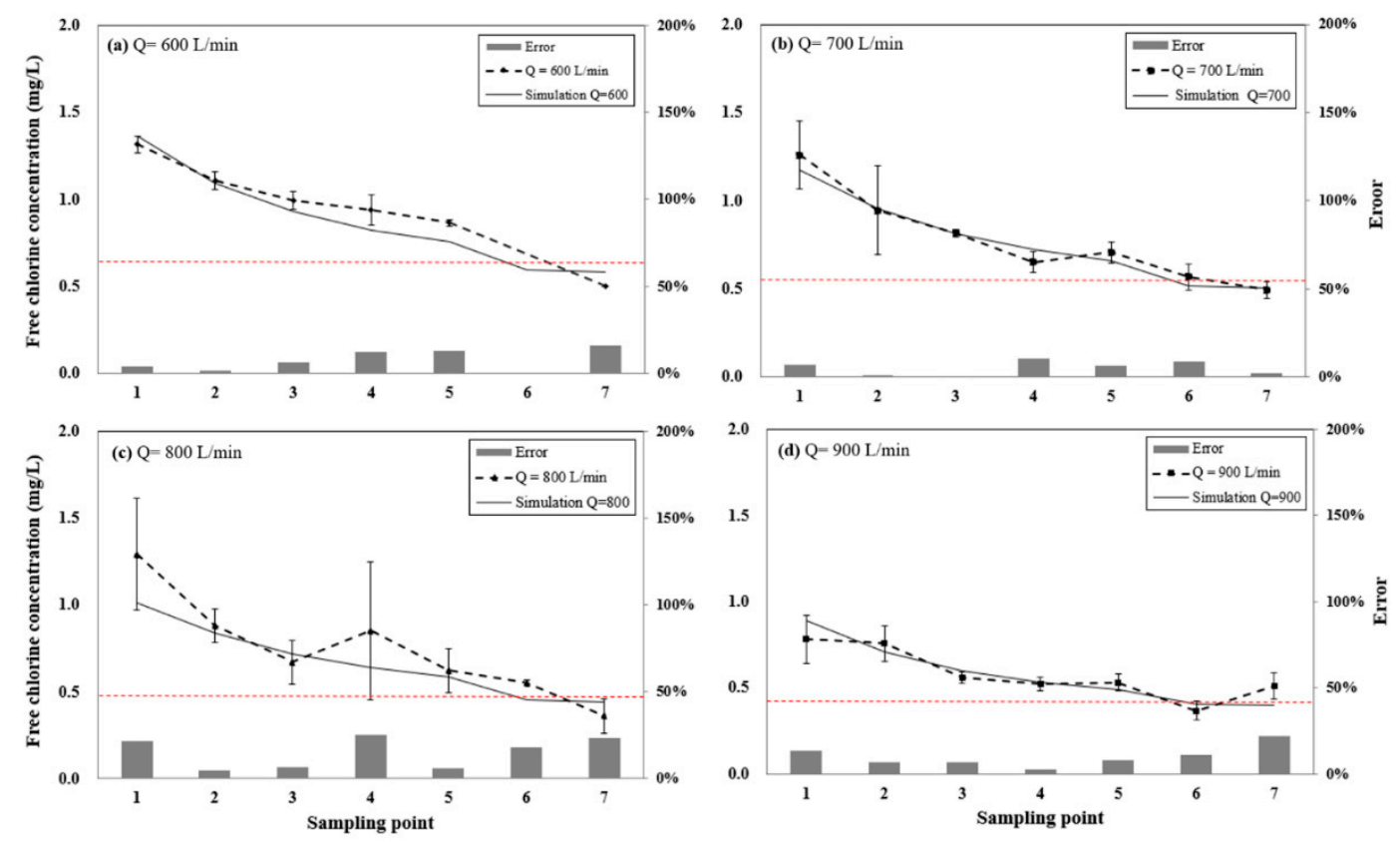

Figure 6. Free chlorine distribution along the sampling ports under different flow rates. Each dot represents experimental data, and each point on the black line is the expected chlorine concentration obtained from computational fluid dynamics (CFD) simulation with a parallel first-order decay model. The red-dotted line is the desirable concentration at the given flow rate: (a) $600 \mathrm{~L} \mathrm{~min}^{-1}$ of flow rate, (b) $700 \mathrm{~L} \mathrm{~min}^{-1}$ of flow rate, (c) $800 \mathrm{~L} \mathrm{~min}^{-1}$ of flow rate, (d) $900 \mathrm{~L} \mathrm{~min}^{-1}$ of flow rate.

The experiment and simulation results, including error, are summarized in Table 2. No significant difference was found in either case both with and without the decay kinetics because the elapsed time was too short for such differences to manifest (3-6 s was required for chlorine from the electrodes to reach sampling port 7). Thus, little chlorine decay was observed while the water passed through the pipe. However, if the pipeline is extended to $100 \mathrm{~m}$, the expected chlorine concentrations with and 
without the decay kinetics are estimated to be 0.22 and $0.45 \mathrm{mg} \mathrm{L}^{-1}$, respectively. Therefore, the decay kinetics must be considered.

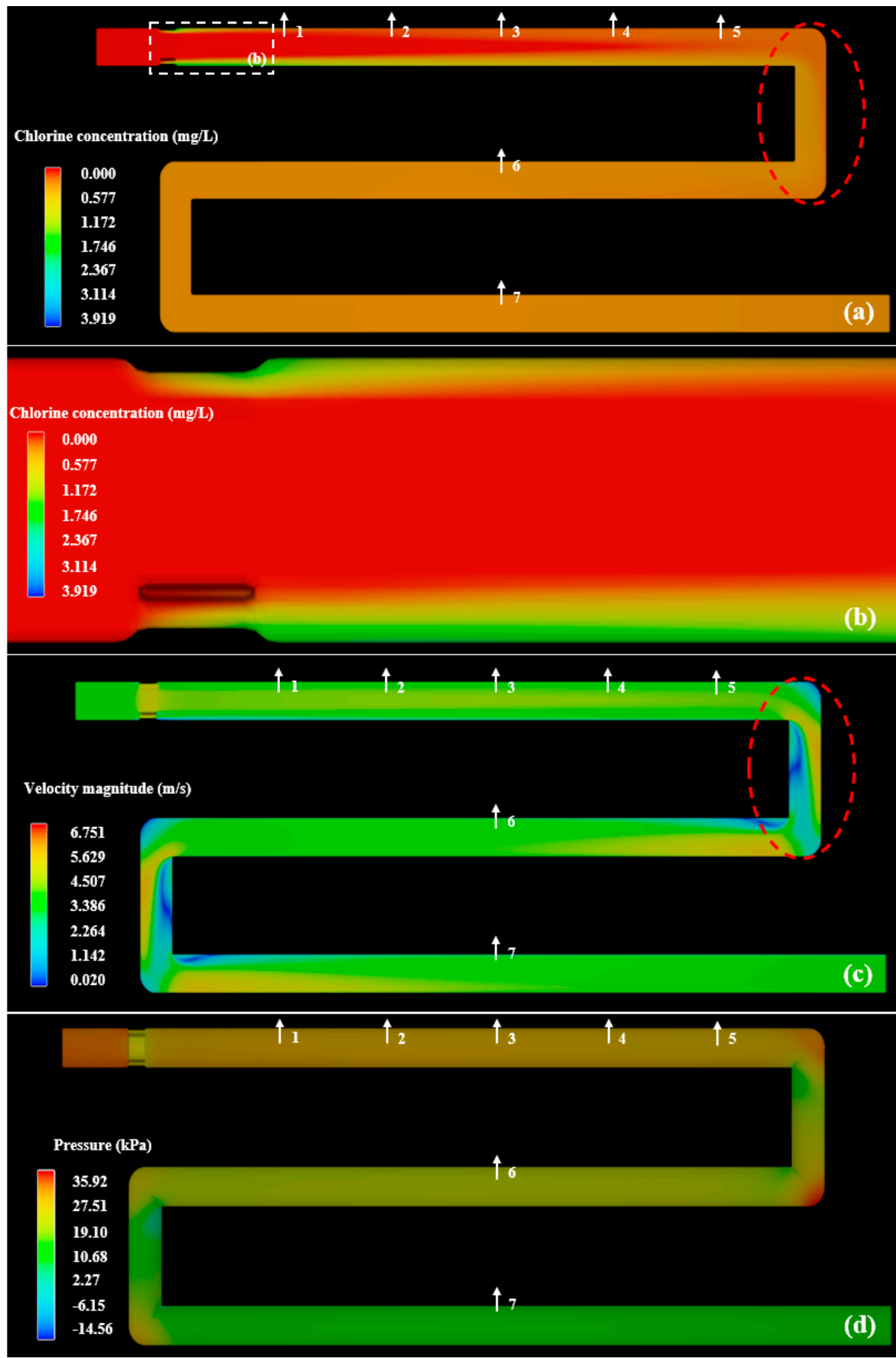

Figure 7. Fluid contour images from CFD simulation of the electro-chlorination experiment. Inlet flow rate is $800 \mathrm{~L} \mathrm{~min}^{-1}$. Outlet pressure was set to $10.8 \mathrm{kPa}$. (a) Chlorine concentration; (b) expanded view of electrode side in image (a); (c) velocity magnitude; (d) pressure. 
The average error between the simulated and experimental results varied from $5 \%$ to $15 \%$. Considering that the simulation results are expressed as time-averaged values, inevitably there would be some error between the real and simulated values. Furthermore, the Reynolds number obtained from our experiment ranged from 12,700 to 13,000 depending on the flow rate, indicating strong turbulence. However, the simulation results fit the experiment data well even under intensively turbulent conditions.

Table 2. Free chlorine concentrations in the electro-chlorination experiment.

\begin{tabular}{|c|c|c|c|c|c|c|c|c|c|}
\hline \multirow{2}{*}{ Flow Rate } & \multirow{2}{*}{$\begin{array}{l}\text { Chlorine Concentration } \\
\left(\mathrm{mg} \mathrm{L}^{-1}\right)\end{array}$} & \multicolumn{7}{|c|}{ Sampling Ports } & \multirow{2}{*}{ Avg } \\
\hline & & 1 & 2 & 3 & 4 & 5 & 6 & 7 & \\
\hline \multirow{5}{*}{$\begin{array}{c}600 \\
\mathrm{~L} \min ^{-1}\end{array}$} & Experiment & 1.32 & 1.11 & 0.99 & 0.94 & 0.86 & No data & 0.50 & \\
\hline & Simulation with decay kinetics & 1.37 & 1.09 & 0.93 & 0.83 & 0.75 & 0.60 & 0.58 & \\
\hline & Simulation without decay kinetics & 1.37 & 1.10 & 0.94 & 0.84 & 0.77 & 0.63 & 0.63 & \\
\hline & Error with decay kinetics (\%) & 4 & 1 & 6 & 12 & 13 & - & 16 & 9 \\
\hline & Error without decay kinetics (\%) & 4 & 0 & 5 & 11 & 11 & - & 26 & 9 \\
\hline \multirow{5}{*}{$\begin{array}{c}700 \\
\mathrm{~L} \min ^{-1}\end{array}$} & Experiment & 1.26 & 0.94 & 0.82 & 0.65 & 0.71 & 0.57 & 0.49 & \\
\hline & Simulation with decay kinetics & 1.17 & 0.95 & 0.81 & 0.72 & 0.66 & 0.52 & 0.50 & \\
\hline & Simulation without decay kinetics & 1.18 & 0.96 & 0.82 & 0.73 & 0.67 & 0.54 & 0.54 & \\
\hline & Error with decay kinetics (\%) & 7 & 1 & 0 & 11 & 7 & 9 & 2 & 5 \\
\hline & Error without decay kinetics (\%) & 6 & 2 & 1 & 13 & 5 & 4 & 10 & 6 \\
\hline \multirow{5}{*}{$\begin{array}{c}800 \\
\mathrm{~L} \mathrm{~min}^{-1}\end{array}$} & Experiment & 1.29 & 0.88 & 0.67 & 0.85 & 0.62 & 0.55 & 0.36 & \\
\hline & Simulation with decay kinetics & 1.01 & 0.84 & 0.72 & 0.64 & 0.58 & 0.45 & 0.44 & \\
\hline & Simulation without decay kinetics & 1.02 & 0.85 & 0.72 & 0.65 & 0.59 & 0.47 & 0.47 & \\
\hline & Error with decay kinetics (\%) & 21 & 5 & 7 & 25 & 6 & 18 & 23 & 15 \\
\hline & Error without decay kinetics (\%) & 21 & 4 & 8 & 24 & 5 & 14 & 31 & 15 \\
\hline \multirow{5}{*}{$\begin{array}{c}900 \\
\text { L min }\end{array}$} & Experiment & 0.78 & 0.76 & 0.56 & 0.52 & 0.53 & 0.37 & 0.51 & \\
\hline & Simulation with decay kinetics & 0.89 & 0.71 & 0.60 & 0.53 & 0.49 & 0.41 & 0.40 & \\
\hline & Simulation without decay kinetics & 0.89 & 0.71 & 0.60 & 0.54 & 0.50 & 0.42 & 0.42 & \\
\hline & Error with decay kinetics (\%) & 13 & 7 & 7 & 2 & 8 & 11 & 22 & 10 \\
\hline & Error without decay kinetics (\%) & 14 & 6 & 8 & 4 & 7 & 15 & 17 & 10 \\
\hline
\end{tabular}

\subsection{Estimated Chlorine Profile of the Full-Scale Cooling System Installed with In-Situ} Electro-Chlorine Generator

To evaluate the chlorine dynamics along a full-scale cooling system with in-situ electro-chlorine generator, the simulation was performed based on the cooling system of a full-scale power plant in Korea (a pressurized-water reactor $1400 \mathrm{MW}$ nuclear power plant). The simulated result for the full-scale cooling system is shown in Figure 8.

Two different cathode positions were simulated. In both cases, the generated chlorine did not mix well. Even though Reynolds number was over one million, chlorine flowed along the inner wall of the pipe. This is because concentrations were calculated as time-averaged values. In addition, the simulation domain of Figure 8 was not long enough to display the ultimate state of the chlorine diffusion.

Figure 9 presents a comparison of the estimated chlorine demands of in-situ electro-chlorination and direct chlorine injection in a full-scale application. For this estimation, the following conditions were considered:

1. A straight cooling-water pipeline with a $2 \mathrm{~m}$ diameter and $1 \mathrm{~km}$ length (no elevation).

2. The residual concentration of chlorine was set to $0.5 \mathrm{mg} \mathrm{L}^{-1}$ in the pipeline.

3. The chlorine decay kinetics was applied in both cases.

For the case of direct chlorine injection, it was assumed the chlorine is uniformly distributed when injected into the pipeline due to a limitation on defining chlorine injection method. For in-situ electro-chlorination, a series of electrodes were assumed. The chlorine concentration was estimated based on the simulated results of the first $10 \mathrm{~m}$ because of the cost limitations associated with a full-scale 
simulation. Figure 9a compares the chlorine concentration along the surface of the pipe between the cases of in-situ electro-chlorination and direct chlorine injection. After passing through the first $50 \mathrm{~m}$ of pipe, the chlorine concentration of the in-situ case was reduced to $0.5 \mathrm{mg} \mathrm{L}^{-1}$ mainly due to diffusion. As a result, the second electrode should be installed at $50 \mathrm{~m}$ apart within such a system. On the other hand, the chlorine concentration of the direct injection case in which water mixed well with chlorine was stable around $0.65 \mathrm{mg} \mathrm{L}^{-1}$, which was expected to be lower than $0.5 \mathrm{mg} \mathrm{L}^{-1}$ at the end of the pipe due to chlorine decay. Figure $9 \mathrm{~b}$ presents the relative chlorine demands of each case. It was estimated that in-situ electro-chlorination would demand only $1 / 3$ of chlorine dose that is required by the direct chlorine injection, even though in-situ electro-chlorination could generate higher chlorine concentrations along the surface of the pipes (exceeding $0.5 \mathrm{mg} \mathrm{L}^{-1}$ ) (Figure 9a).

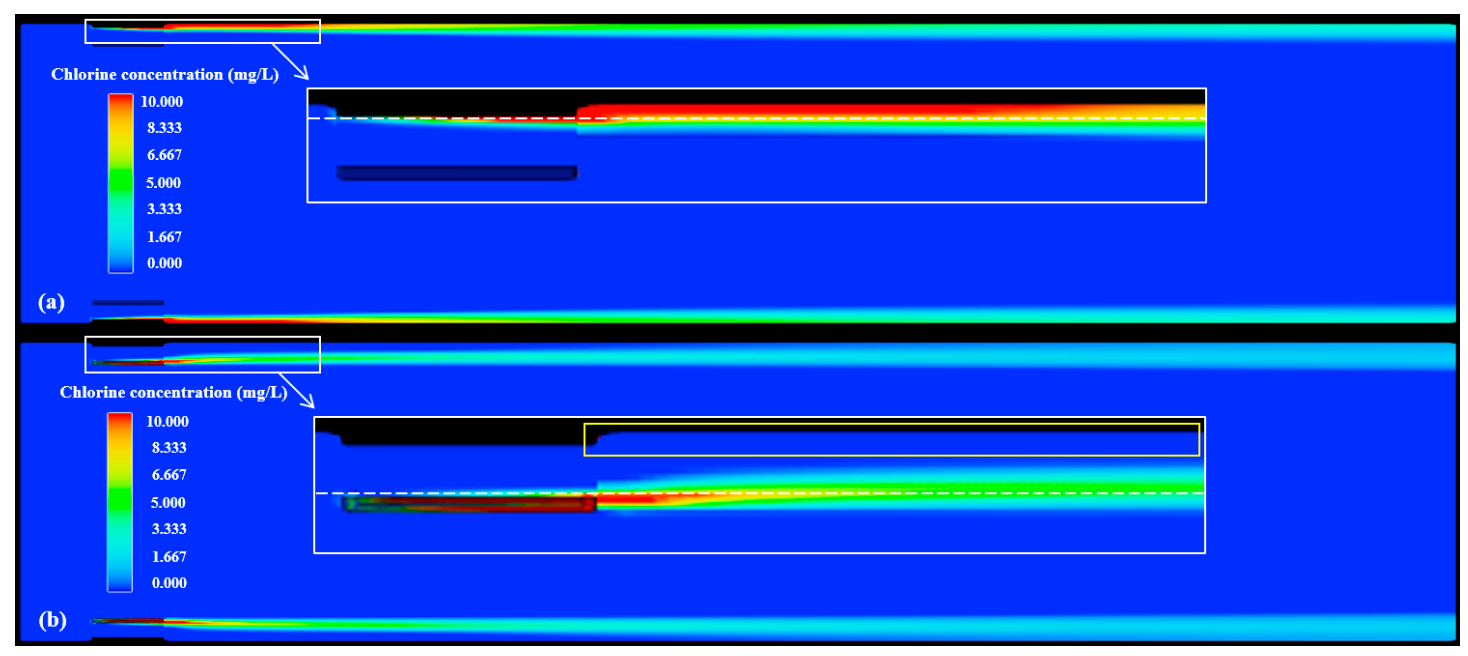

Figure 8. Chlorine concentration contour in the simulation of full-scale in-situ electro-chlorination with different cathode positions. The pipe diameter is $2 \mathrm{~m}$ and the flow rate is $14 \mathrm{~m}^{3} \mathrm{~s}^{-1}$. The figure shows $10 \mathrm{~m}$ of the pipeline. (a) The simulation result when the cathode is placed on the surface of the pipe wall. (b) The simulation result when the cathode is placed on the inside of the pipe with $100 \mathrm{~mm}$ of distance from the pipe wall.
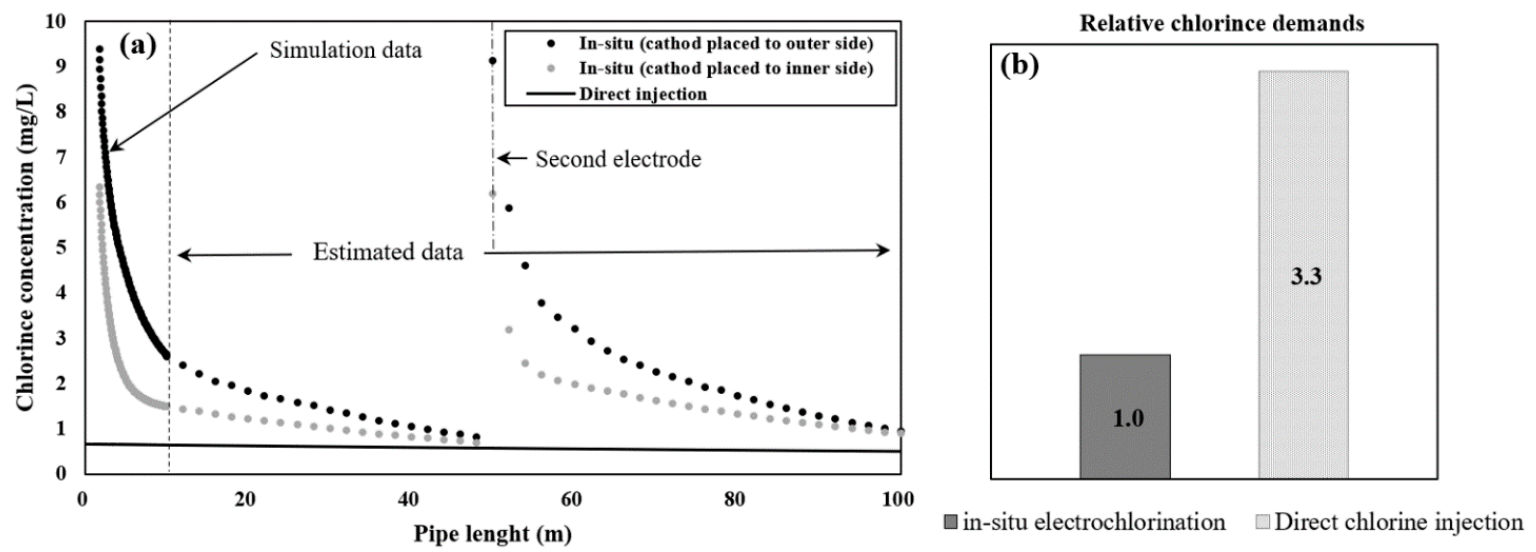

Figure 9. Comparison of in-situ electro-chlorination and direct chlorine injection in full-scale applications.

(a) Estimated chlorine concentrations along the pipe surface. (b) Relative chlorine demands.

While the simulation provides insight into the feasibility of in-situ chlorination for practical applications, this estimation does not consider pipe curvature, fluid elevation, or any other structures that might be placed in the fluid path. Real chlorine demands can vary depending on the conditions in individual power plants. 
The cooling pipes of power plants are often large both in diameter and length, so they can carry a large volume of water [37]. Nevertheless, the biofouling induced by marine organisms is more common near the intaking region [38]. Therefore, intensive chlorination is often practiced at the intaking region. The main disadvantages of this practice are consumption of large amounts of chlorine so as to increase chlorine concentration of whole cooling water and difficulty in controlling chlorine levels at the end of cooling systems. On the other hand, in-situ electro-chlorination can produce chlorine along the pipe wall to save chlorine dose. In fact, the direct chlorine injection often uses electrolysis to produce chlorine on site, therefore, the operational costs of both methods can be compared with the amount of chlorine produced. Reported operational expenditure (OPEX) of on-site electro-chlorination is approximately 1,400,000 USD per year in the case of $18 \mathrm{~m}^{3} \mathrm{~s}^{-1}$ of cooling water flow [39]. In that case, approximately 424,000 USD per year could be saved. As shown in Figure 9, several electrodes can be installed at a certain distance along a pipeline. Since chlorine is generated in-situ via electrochemical process, a control scheme (e.g., the one based on an oxidation-reduction potential (ORP) sensor [40]) can be easily implemented [41]; this will be a future study.

\section{Conclusions}

A parallel first-order kinetics model was applied to simulate chlorine dynamics along a pilot-scale cooling system with in-situ electro-chlorination. Firstly, TOC-based rate constants were obtained by applying the chlorine decay model for the experimental data from batch experiments. The fitted model could well predict the data $\left(R^{2}\right.$ of 0.919$)$. Then the kinetics parameters were input to the decay model incorporated in a CFD code made for a pilot-scale in-situ electro-chlorination system. Incremental differences in chlorine concentrations near the pipe wall of the cooling system were found both in the simulation and in the pilot-scale experiment with less than $15 \%$ error. Higher chlorine concentrations were maintained along the surface of the pipeline within a certain distance from the electrodes, eventually reducing the chlorine demand of the system. A full-scale simulation with kinetics model suggested that the chlorine demand by the electrochemical chlorination for cooling systems would be only $1 / 3$ of that by the direct chlorine injection system. Thus, if electrodes are well-configured and carefully controlled via modeling, like the case of this study, or sensors, a more cost-effective and environmentally friendly in-situ electro-chlorination could be achieved for power plants in coastal area.

Supplementary Materials: The following are available online at http://www.mdpi.com/2076-3417/10/13/4455/s1, Figure S1: The sensitivity test result of each parameter, Table S1: Simulation set-up information.

Author Contributions: Conceptualization, H.K. and B.-I.S.; methodology, H.K.; data collection, J.Y., J.L. and M.A.F.; investigation, J.Y., J.L. and M.A.F.; writing-original draft preparation, J.Y.; writing—review and editing, H.K.; visualization, J.Y. and J.L.; supervision, H.K.; project administration, H.K. and B.-I.S.; funding acquisition, B.-I.S. and H.K. All authors have read and agreed to the published version of the manuscript.

Funding: This work was supported by the Korea Institute of Energy Technology Evaluation and Planning (KETEP) and the Ministry of Trade, Industry and Energy (MOTIE) of the Republic of Korea (No. 20171520101740).

Conflicts of Interest: The authors declare no conflict of interest.

\section{References}

1. Macknick, J.; Newmark, R.; Heath, G.; Hallett, K.C. Operational water consumption and withdrawal factors for electricity generating technologies: A review of existing literature. Environ. Res. Lett. 2012, 7, 045802. [CrossRef]

2. Pan, S.-Y.; Snyder, S.W.; Packman, A.I.; Lin, Y.J.; Chiang, P.-C. Cooling water use in thermoelectric power generation and its associated challenges for addressing water-energy nexus. Water-Energy Nexus 2018, 1, 26-41. [CrossRef]

3. Feeley, T.J., III; Skone, T.J.; Stiegel, G.J., Jr.; McNemar, A.; Nemeth, M.; Schimmoller, B.; Murphy, J.T.; Manfredo, L. Water: A critical resource in the thermoelectric power industry. Energy 2008, 33, 1-11. [CrossRef] 
4. World Nuclear Association. World Nuclear Performance Report 2016; World Nuclear Association: London, UK, 2016.

5. Pugh, S.; Hewitt, G.; Müller-Steinhagen, H. Fouling during the use of seawater as coolant-The development of a user guide. Heat Transf. Eng. 2005, 26, 35-43. [CrossRef]

6. Satpathy, K.K.; Mohanty, A.K.; Sahu, G.; Biswas, S.; Prasad, M.; Slvanayagam, M. Biofouling and its control in seawater cooled power plant cooling water system-A review. Nucl. Power 2010, 17, 191-242.

7. Cristiani, P.; Perboni, G. Antifouling strategies and corrosion control in cooling circuits. Bioelectrochemistry 2014, 97, 120-126. [CrossRef] [PubMed]

8. Walker, M.E.; Safari, I.; Theregowda, R.B.; Hsieh, M.-K.; Abbasian, J.; Arastoopour, H.; Dzombak, D.A.; Miller, D.C. Economic impact of condenser fouling in existing thermoelectric power plants. Energy 2012, 44, 429-437. [CrossRef]

9. Yi, J.; Ahn, Y.; Hong, M.; Kim, G.-H.; Shabnam, N.; Jeon, B.; Sang, B.-I.; Kim, H. Comparison between $\mathrm{OCl}-$-Injection and In Situ Electrochlorination in the Formation of Chlorate and Perchlorate in Seawater. Appl. Sci. 2019, 9, 229. [CrossRef]

10. Xue, Y.; Zhao, J.; Qiu, R.; Zheng, J.; Lin, C.; Ma, B.; Wang, P. In Situ glass antifouling using Pt nanoparticle coating for periodic electrolysis of seawater. Appl. Surf. Sci. 2015, 357, 60-68. [CrossRef]

11. Mahfouz, A.B.; Atilhan, S.; Batchelor, B.; Linke, P.; Abdel-Wahab, A.; El-Halwagi, M.M. Optimal scheduling of biocide dosing for seawater-cooled power and desalination plants. Clean Technol. Environ. Policy 2011, 13, 783-796. [CrossRef]

12. Rubio, D.; López-Galindo, C.; Casanueva, J.F.; Nebot, E. Monitoring and assessment of an industrial antifouling treatment. Seasonal effects and influence of water velocity in an open once-through seawater cooling system. Appl. Therm. Eng. 2014, 67, 378-387. [CrossRef]

13. European Integrated Pollution Prevention and Control (IPPC) Bureau, European Commission. Reference Document on the Application of Best Available Techniques to Industrial Cooling Systems December 2001; European Commission, Tech. Rep.: Brussels, Belgium, 2001.

14. Venkatesan, R.; Murthy P., S. Macrofouling Control in Power Plants. In Springer Series on Biofilms; Springer: Berlin/Heidelberg, Germany, 2008.

15. Kastl, G.; Fisher, I.; Jegatheesan, V. Evaluation of chlorine decay kinetics expressions for drinking water distribution systems modelling. J. Water Supply Res. Technol. AQUA 1999, 48, 219-226. [CrossRef]

16. Fisher, I.; Kastl, G.; Sathasivan, A.; Cook, D.; Seneverathne, L. General model of chlorine decay in blends of surface waters, desalinated water, and groundwaters. J. Environ. Eng. 2015, 141, 04015039. [CrossRef]

17. Fisher, I.; Kastl, G.; Sathasivan, A.; Jegatheesan, V. Suitability of chlorine bulk decay models for planning and management of water distribution systems. Crit. Rev. Environ. Sci. Technol. 2011, 41, 1843-1882. [CrossRef]

18. Fisher, I.; Kastl, G.; Sathasivan, A. Evaluation of suitable chlorine bulk-decay models for water distribution systems. Water Res. 2011, 45, 4896-4908. [CrossRef] [PubMed]

19. Haas, C.N.; Karra, S. Kinetics of wastewater chlorine demand exertion. J. (Water Pollut. Control Fed.) 1984, 56, 170-173.

20. Zeng, J.; Jiang, Z.; Chen, Q.; Zheng, P.; Huang, Y. The decay kinetics of residual chlorine in cooling seawater simulation experiments. Acta Oceanol. Sin. 2009, 28, 54-59.

21. Saeed, S.; Prakash, S.; Deb, N.; Campbell, R.; Kolluru, V.; Febbo, E.; Dupont, J. Development of a site-specific kinetic model for chlorine decay and the formation of chlorination by-products in seawater. J. Mar. Sci. Eng. 2015, 3, 772-792. [CrossRef]

22. Al Heboos, S.; Licskó, I. Application and comparison of two chlorine decay models for predicting bulk chlorine residuals. Period. Polytech. Civ. Eng. 2017, 61, 7-13. [CrossRef]

23. Shadloo, M.S.; Oger, G.; Le Touzé, D. Smoothed particle hydrodynamics method for fluid flows, towards industrial applications: Motivations, current state, and challenges. Comput. Fluids 2016, 136, 11-34. [CrossRef]

24. Wols, B.; Hofman, J.; Uijttewaal, W.; Rietveld, L.; Van Dijk, J. Evaluation of different disinfection calculation methods using CFD. Environ. Model. Softw. 2010, 25, 573-582. [CrossRef]

25. Angeloudis, A.; Stoesser, T.; Falconer, R.A. Predicting the disinfection efficiency range in chlorine contact tanks through a CFD-based approach. Water Res. 2014, 60, 118-129. [CrossRef] [PubMed]

26. Zhang, J.; Tejada-Martínez, A.E.; Zhang, Q. Developments in computational fluid dynamics-based modeling for disinfection technologies over the last two decades: A review. Environ. Model. Softw. 2014, 58, 71-85. [CrossRef] 
27. Lim, Y.H.; Deering, D.D. Modeling Chlorine Residual in a Ground Water Supply Tank for a Small Community in Cold Conditions, World Environmental and Water Resources Congress 2017; American Society of Civil Engineers: Reston, VA, USA, 2017; pp. 124-138.

28. Hernández-Cervantes, D.; Delgado-Galván, X.; Nava, J.L.; López-Jiménez, P.A.; Rosales, M.; Mora Rodríguez, J. Validation of a computational fluid dynamics model for a novel residence time distribution analysis in mixing at cross-junctions. Water 2018, 10, 733. [CrossRef]

29. Hua, F.; West, J.; Barker, R.; Forster, C. Modelling of chlorine decay in municipal water supplies. Water Res. 1999, 33, 2735-2746. [CrossRef]

30. Jonkergouw, P.M.; Khu, S.-T.; Savic, D.A.; Zhong, D.; Hou, X.Q.; Zhao, H.-B. A variable rate coefficient chlorine decay model. Environ. Sci. Technol. 2009, 43, 408-414. [CrossRef]

31. Nejjari, F.; Puig, V.; Pérez, R.; Quevedo, J.; Cugueró, M.; Sanz, G.; Mirats, J. Chlorine decay model calibration and comparison: Application to a real water network. Procedia Eng. 2014, 70, 1221-1230. [CrossRef]

32. Kohpaei, A.J.; Sathasivan, A.; Aboutalebi, H. Effectiveness of parallel second order model over second and first order models. Desalin. Water Treat. 2011, 32, 107-114. [CrossRef]

33. Powell, J.C.; Hallam, N.B.; West, J.R.; Forster, C.F.; Simms, J. Factors which control bulk chlorine decay rates. Water Res. 2000, 34, 117-126. [CrossRef]

34. Clark, R.M.; Sivaganesan, M. Predicting chlorine residuals in drinking water: Second order model. J. Water Resour. Plan. Manag. 2002, 128, 152-161. [CrossRef]

35. Li, X.; Li, C.; Bayier, M.; Zhao, T.; Zhang, T.; Chen, X.; Mao, X. Desalinated seawater into pilot-scale drinking water distribution system: Chlorine decay and trihalomethanes formation. Desalin. Water Treat. 2016, 57, 19149-19159. [CrossRef]

36. United States Environmental Protection Agency (EPA). Chlorine, Total Residual (Spectrophotometric, DPD); EPA-NERL: 330.5; EPA: Cincinnati, OH, USA, 1978.

37. Polman, H.; Verhaart, F.; Bruijs, M. Impact of biofouling in intake pipes on the hydraulics and efficiency of pumping capacity. Desalin. Water Treat. 2013, 51, 997-1003. [CrossRef]

38. Rajagopal, S.; Van der Velde, G.; Van der Gaag, M.; Jenner, H.A. How effective is intermittent chlorination to control adult mussel fouling in cooling water systems? Water Res. 2003, 37, 329-338. [CrossRef]

39. Bruijs, M.C.; Venhuis, L.P.; Daal, L. Global Experiences in Optimizing Biofouling Control through Pulse-Chlorination@. 2017. Available online: https://www.researchgate.net/publication/318561645_Global_ Experiences_in_Optimizing_Biofouling_Control_through_Pulse-ChlorinationR (accessed on 1 May 2020).

40. Kim, H.; Hao, O.J.; McAvoy, T.J. Comparison between model-and pH/ORP-based process control for an AAA system. Tamkang J. Sci. Eng. 2000, 3, 165-172.

41. Brdys, M.; Chang, T.; Duzinkiewicz, K. Intelligent Model Predictive Control of Chlorine Residuals in Water Distribution Systems, Bridging the Gap: Meeting the World's Water and Environmental Resources Challenges. In Proceedings of the ASCE Water Resource Engineering and Water Resources Planning and Management, Minneapolis, MN, USA, 30 July-2 August 2000; pp. 1-11.

(C) 2020 by the authors. Licensee MDPI, Basel, Switzerland. This article is an open access article distributed under the terms and conditions of the Creative Commons Attribution (CC BY) license (http://creativecommons.org/licenses/by/4.0/). 